\section{Knowledge and practice of breast self-examination among undergraduate students in Bahir Dar University, North-West Ethiopia, 2016: A cross-sectional study}

\author{
Tilahun Tewabe, Zelalem Mekuria \\ Bahir Dar University, College of \\ Medicine and Health Science, Bahir Dar, \\ Ethiopia
}

\begin{abstract}
Breast cancer is the most common cancer in women worldwide, with nearly 1.7 million new cases diagnosed each year which accounts $12 \%$ of all new cancer cases and $25 \%$ of all cancers in women. Breast self-examination offers women the best opportunity for reducing breast cancer deaths. From a total of 222 respondents about $190(85.6 \%)$ heard about breast selfexamination. One hundred forty-three (75.3\%) had good knowledge about sign and symptoms of breast cancer and 47 $(24.7 \%)$ had poor knowledge about the sign and symptoms of breast cancer. From total respondents of the study $120(54.1 \%)$ practiced breast self-examination. Breast selfexamination practice is relatively frequent problem in Bahir Dar University, health science students. Negligence, forgetfulness and lack of knowledge are the main factors for poor practice of breast self-examination. Public health education using the media, clubs and leaflet could significantly reduce poor practice of breast self-examination and increases early detection of breast lump.
\end{abstract}

\section{Introduction}

Cancer is a leading cause of death worldwide, accounting for $8.2 \%$ deaths in $2012 .^{1}$ Breast cancer is the most common cancer among women worldwide, claiming the lives of hundreds of thousands of women each year and affecting countries at all levels of modernizations. ${ }^{2}$

Breast self-examination (BSE) is a screening method used in an attempt to detect early breast cancer, the method involves the women herself looking at and feeling each breast for possible lumps, distortions or swelling. ${ }^{3}$

Each year it is estimated that over 230,000 women in United States are diagnosed with cancer and more than 40,000 will die. ${ }^{4}$ In France the breast cancer at risk population increased from approximately 19 million women in 1990 to approximately 21 million in 2010. In Nigeria on the other hand, the number of women at risk of breast cancer increased steadily from approximately 24.5 million in 1990 to approximately 40 million in $2010 .{ }^{5}$ Breast cancer is the third commonest cancer in women in Uganda after Kaposi's sarcoma and cervical cancer. Breast cancer incidence in Uganda is $22: 100,000$. Five-year survival rate is $56 \%$. In Nigeria, the incidence of breast cancer has been reported to be 33.6/100,000.6,7

Breast cancer is the second most often occurring cancer among women in Ethiopia. It is estimated that around 10,000 Ethiopian women and men have breast cancer with thousands of more cases unreported as women living in rural areas often seek treatment from traditional healers before seeking help. Women who practice breast self-examination regularly present with smaller tumor and earlier stages of disease. It is estimated that only minority of women ( 25 to $30 \%$ ) perform breast self-examination each month. ${ }^{8}$

The objective of this study was to assess the knowledge and practice of breast selfexamination (BSE) among health science regular female undergraduate students in Bahir Dar University, Ethiopia.

\section{Materials and Methods}

An institution based quantitative crosssectional study was conducted from April 10 to May 10, 2016. The study was conducted in Bahir Dar University among college of health science regular female undergraduate students. Bahir Dar University is located in Bahir Dar town which is located in North West of Ethiopia $565 \mathrm{~km}$ away from Addis Ababa, capital city of Ethiopia. The University has four colleges, three institutes, three faculties and five schools. The study was conducted among 459 regular female students in college of health sciences.

The sample size was calculated using a single population proportion formula by considering the following assumptions: proportion of breast self-examination $=50 \%$, level of confidence $=95 \%$, margin of error $=5 \%$ and after applying correction formula and $10 \%$ non- response rate the final sample size was 222 .

Data was collected using structured self-administered semi structured questionnaire. The questionnaire was constructed by adopting from previous research done on similar topic and modified accordingly. The data was collected by two third year mid-
Correspondence: Tilahun Tewabe, Bahir Dar University, College of Medicine and Health Science, Bahir Dar, Ethiopia.

E-mail: bezatewabe01@gmail.com

Key words: knowledge and practice of breast self-examination, college of health sciences, Bahir Dar University, North West, Ethiopia.

Acknowledgements: First and most the authors would like to express deep gratitude and appreciation to Bahir Dar University, College of Medicine and Health Science, and Department of Nursing, for giving the opportunity to do this research. They would like to express deep gratitude to Bahir Dar University health science registrar which helped them to know the total number of female students under the college. Finally, they would like to thank all who helped them throughout this research project.

Contributions: TT contributed to the design of this study. Authors conceived and designed study, collected, analyzed and interpreted data; drafted the manuscript for important intellectual content. The authors reviewed and revised the draft further and approved the final version for submission.

Conflict of interest: the authors declare no potential conflict of interest.

Funding: the source of funding for this research manuscript is Bahir Dar University.

Received for publication: 21 October 2017. Accepted for publication: 19 July 2018.

This work is licensed under a Creative Commons Attribution NonCommercial 4.0 License (CC BY-NC 4.0).

(C) Copyright T. Tewabe and Z. Mekuria, 2019 Licensee PAGEPress, Italy

Journal of Public Health in Africa 2019; 10:805 doi:10.4081/jphia.2019.805

wifery and two third year nursing students. One day training was given for data collectors. Pretest was done on regular extension female students before the actual data collection started on $5 \%$ of sample size. Necessary modification like appropriate wording of questions was taken based on the finding of the pretest.

\section{Operational definition}

Knowledge of breast self-examination: was measured by considering those who answered $70 \%$ and above of BSE questions as knowledgeable, and those who got $<70 \%$ non-knowledgeable. ${ }^{9}$

Practice of BSE: defined as performing of BSE at regular and the same time each month using proper technique which is evi- 
denced by the result of questionnaire.

Regular BSE: when BSE is performed each month at the same time after some days of menstrual cycle

Occasional BSE: when BSE is 1 to 3 times a year or every 3 months (irregularly at any time).

Clinical breast self-examination: when an experienced health worker examines breasts Statistical Analysis.

The collected data was checked manually for completeness and consistencies, and then it was coded and entered in EPI Info version 3.5.3 and exported to SPSS version 16 for analysis. Descriptive statistics was used to summarize the socio demographic characteristics of the study participants, knowledge and practice of students regarding to breast self-examination.

\section{Results}

\section{Socio demographic characteristics}

Majority of study participants were single $197(88.7 \%)$ and most of them 174 (78.4\%) were orthodox Christian in religion. The age of participants was between 18-40 years and most of our respondents age group is between 18-23 years of age 192 (86.5\%). Regarding to ethnicity 134 (60.4\%) were Amhara, 37(16.7\%) Oromo, $27(12.2 \%)$ Tigre and $10(4.5 \%)$ were Gurage.

\section{Knowledge of participants about BSE}

From a total of 222 respondents 190 $(85.6 \%)$ heard about breast self-examination. Among those who heard BSE, 162 $(85.3 \%)$ had good knowledge about risk factor of breast cancer and 28 (14.7\%) had poor knowledge about risk factor of breast cancer. About 143 (75.3\%) of the participants had good knowledge about sign and symptoms of breast cancer. Participant's level of information on breast self-examination: most of the participants $(85.6 \%)$ heard about BSE. The awareness level of BSE among students was quite high $(80.3 \%)$. Most students got first information about BSE: through lecture $(53.2 \%)$, mass media $(22.1 \%)$, and from health personnel (18.4\%). Regarding participants knowledge on techniques of BSE: 47 (22.1\%) said circular technique is the correct one, 24 $(12.6 \%)$ respond wedge technique (dividing breasts in to quadrants), 9 vertical strip technique and $78(41.1 \%)$ agreed on all techniques (Table 1).

\section{Practice of participants about BSE}

From total respondents, 120 (54.1\%) performed breast self-examination whereas
$102(45.9 \%)$ had never performed breast self-examination. Among those who practiced BSE $36(30 \%)$ of them performed BSE regularly each month whereas 84 (70\%) performed BSE occasionally. From all study participants $56(46.7 \%)$ have done BSE before one month, 25 (20.8\%) before six months, $31(25.8 \%)$ before one year and eight have never done BSE before the last one year. Ten of study participants have discovered a lump and 7 of them were consulted a doctor (Table 2).

\section{Discussion}

Breast self-examination is a screening method used in an attempt to detect early breast cancer, the method involves the women herself looking at and feeling each breast for possible lumps, distortions or swelling. ${ }^{1}$

The participants level of awareness of BSE was significantly high (80.3\%), implying that students of CHS have good awareness of the disease, although only 102 $(45.9 \%)$ believed that breast cancer is a curable disease.

This study indicated benefit of performing BSE but only 43 (19.1\%) understood for early discovery and treatment of breast lump and other described it as follow: 39 $(20.5 \%)$ believed that it helps the individual to know the shape and size of breasts, 7 $(3.7 \%)$ respond that it is to check the change on the color of skin of breasts while 14 (7.4\%) did not know the purpose of BSE. A similar study performed in Nigeria reported that only $22 \%$ understood that it helps in early detection of breast lump, and other described it as follows: $:^{7} 18 \%$ believed that it helps the individual to know the shape and size of her breasts while $24 \%$ did not have any idea of what it is. This may be due to the increased awareness about BSE through mass Medias and educational institutions.

The present investigation indicated that although a majority of students know about breast cancer only $54.1 \%$ actually practiced BSE. There is a wide gap between knowledge and practice among CHS undergraduate female students regarding BSE. This finding is in concordance with other studies reported from Africa, Asia and America. ${ }^{10}$ In a similar study in Klang Valley, Malaysia, ${ }^{11}$ reported that $50 \%$ of participants have good knowledge about breast self-examination and only $155(19.6 \%)$ of them practiced BSE. This may be due to lack of facilities for privacy and cultural misconception as doing repeated BSE

Table 1. Knowledge participants about risk factors and sign and symptoms of breast cancer among Bahir Dar University CHS regular female undergraduate students, Bahir Dar, North West Ethiopia, 2016.

\begin{tabular}{lccc}
\hline Variables & Yes/No & Frequency & $\%$ \\
Increase in age & Yes & 171 & 90 \\
High fat diet & Yes & 126 & 66.3 \\
\hline Smoking & Yes & 167 & 87.9 \\
Working class women & Yes & 80 & 42.1 \\
\hline Alcohol consumption & Yes & 156 & 82.1 \\
First child at late age & Yes & 127 & 66.8 \\
\hline Early onset of menarche & Yes & 111 & 58.4 \\
Late menopause & Yes & 124 & 55.3 \\
\hline Stress & Yes & 128 & 67.4 \\
Larger breast & Yes & 72 & 37.9 \\
\hline Lump in the breast & Yes & 171 & 90 \\
Discharge from the breast & Yes & 163 & 85.8 \\
\hline Pain or soreness in the breast & Yes & 169 & 88.9 \\
Change in size of breast & Yes & 164 & 66.3 \\
\hline Discoloration/dimpling of the breast & Yes & 171 & 90 \\
Ulceration of the breast & Yes & 152 & 80 \\
\hline Weight loss & Yes & 130 & 68.4 \\
Changes in the shapes of breast & Yes & 161 & 84.7 \\
\hline Inversion/pulling in of nipple & Yes & 158 & 83.2 \\
Swelling/enlargement of breast & Yes & 170 & 89.5 \\
\hline Lump under armpit & Yes & 155 & 81.6 \\
Scaling/dry skin in nipple region & Yes & 156 & 82.1 \\
\hline & & & \\
\hline & & & \\
\hline
\end{tabular}


Table 2. Practice of respondents towards prevention of breast cancer among Bahir Dar University CHS regular female undergraduate students, Bahir Dar, North West Ethiopia, 2016.

\begin{tabular}{|c|c|c|c|}
\hline Variables & Category & Frequency & $\%$ \\
\hline Have you ever performed BSE & Yes & 120 & 54.1 \\
\hline Reasons for not performing BSE & $\begin{array}{l}\text { Negligence } \\
\text { Forgetfulness } \\
\text { Lack of knowledge } \\
\text { Others }\end{array}$ & $\begin{array}{c}62 \\
24 \\
15 \\
1\end{array}$ & $\begin{array}{c}60.8 \\
23.5 \\
14.7 \\
0.9\end{array}$ \\
\hline How often do you perform BSE & $\begin{array}{l}\text { Regularly each month } \\
\text { Occasionally }\end{array}$ & $\begin{array}{l}36 \\
84\end{array}$ & $\begin{array}{l}30.0 \\
70.0\end{array}$ \\
\hline When did you do BSE & $\begin{array}{l}\text { Before one month } \\
\text { Before six months } \\
\text { Before one year } \\
\text { Never a year }\end{array}$ & $\begin{array}{c}56 \\
25 \\
31 \\
8\end{array}$ & $\begin{array}{l}46.7 \\
20.8 \\
25.8 \\
6.7\end{array}$ \\
\hline Which technique are you using during BSE & $\begin{array}{l}\text { Vertical strip technique } \\
\text { Circular technique } \\
\text { Wedge technique } \\
\text { All } \\
\text { I do not know }\end{array}$ & $\begin{array}{c}13 \\
44 \\
15 \\
39 \\
9\end{array}$ & $\begin{array}{c}10.8 \\
36.7 \\
12.5 \\
32.5 \\
7.5\end{array}$ \\
\hline What are you looking for while performing BSE & $\begin{array}{l}\text { Change in the color of the skin } \\
\text { Shape and size of breast(mass) } \\
\text { Direction of nipples and discharge from nipples } \\
\text { All } \\
\text { I do not know }\end{array}$ & $\begin{array}{c}1 \\
29 \\
1 \\
82 \\
7\end{array}$ & $\begin{array}{c}0.8 \\
24.2 \\
0.8 \\
68.3 \\
5.8\end{array}$ \\
\hline Have you ever discovered a lump (something abnormal) & Yes & 10 & 10.8 \\
\hline What was your immediate action & $\begin{array}{l}\text { Consult relative } \\
\text { Consult to a doctor } \\
\text { Use traditional medicine } \\
\text { Goes to prayer house }\end{array}$ & $\begin{array}{c}7 \\
15 \\
1 \\
2\end{array}$ & $\begin{array}{c}28.0 \\
60.0 \\
4.0 \\
8.0\end{array}$ \\
\hline
\end{tabular}

examination increases the risk of acquiring cancer.

Most of the participants in this study had heard about breast self-examination which was comparable with studies conducted in Nigeria. ${ }^{12}$ From total study participants, $85.6 \%$ of participants heard about BSE which is little higher (82\%) than the Nigerian study. ${ }^{12}$ Regarding the source of knowledge about BSE, similar results were observed in Nigerian study which was $53.2 \%$ of students heard of BSE through lectures, which were the main source of information. In other similar study that was conducted in Ghana ${ }^{13}$ nursing students, the main source of information were mass media $(48 \%)$, and $(16 \%)$ were health personnel. In this study $22.1 \%$ heard through mass media, (18.4\%) from health personnel and $(6.3 \%)$ heard from pamphlet. The difference may be due poor coverage by mass Medias about prevention of breast cancer and importance of early BSE.

This study indicated that majority of students knowledge regarding risk factors and sign symptoms was found to be good, $162(85.3 \%)$ have good knowledge about risk factor of breast cancer which is higher (59\%) than the study done on West Gojjam health extension workers. ${ }^{14}$ Another study which was conducted in Mekele University $^{15}$ reported that only $22.1 \%$ of participants have good knowledge about the sign and symptoms of breast cancer. This may be due to the differences between the study settings, since study is conducted in academic organization in health-related students.

In this study $45.9 \%$ participants had never practiced BSE and 30\% practiced it regularly. The main reasons for not doing BSE was mainly due to negligence 62 $(60.8 \%)$, forgetfulness $24(23.5 \%)$ and lack of knowledge 15 (14.7\%). Most of the students in this study did not perform BSE despite having knowledge which was contrary to the reported studies from Nigeria. ${ }^{12}$ In a similar study in Klang Valley, Malaysia, ${ }^{11}$ reported that only 155 (19.6\%) of them practice BSE. Another study that was conducted in Ghana nursing students, ${ }^{12}$ reported that $76 \%$ of study participants practice BSE. The difference may be due: socio cultural differences between countries, lack information dissemination about BSE and breast cancer through mass Medias.

A limitation of this study is that only the quantitative aspects of breast self-exam assessed. Since is the study is descriptive it has a limitation to find additional determinant factors. Also results may overestimate the practice of breast self-exam since it is done on health science students.

\section{Conclusions}

Overall this finding indicated that the practice of BSE while perceived as being important is not frequently practiced by the students of Bahir Dar university CHS. So much has to be done in educating BSE and their technique. CHS collaborating with regional health bureau and ministry of health shall work on creating awareness to the students regarding advantage of BSE through leaflet, mass media and health education. Further studies are needed to explore what intervention could be best used to improve the uptake and practice of BSE and other methods for early breast cancer detection.

\section{References}

1. Mc Guire S. World cancer report 2014. Adv Nutr 2016;7:418-9.

2. Bilimoria KY, Stewart AK, Winchester DP, Ko CY. The National Cancer Data Base: a powerful initiative to improve cancer care in the United States. Ann Surg Oncol 2008;15:683-90.

3. Ferlay J, Soerjomataram I, Ervik M, et al. GLOBOCAN 2012 v1.1. Cancer Incidence and Mortality Worldwide; IARC Cancer Base No. 11[Internet]. 
Lyon, France; International Agency for Research on Cancer; 2014.

4. American Cancer Society. Cancer facts and figures. Available from: https://www.cancer.org/research/cancer-facts-statistics.html. Accessed on 17/4/2016

5. Akarolo-Anthony SN, Ogundiran TO, Adebamowo CA. Emerging breast cancer epidemic: evidence from Africa. Breast Canc Res 2010;12:S8.

6. Alkhasawneh IM, Akhu-Zaheya LM, Suleiman SM. Jordanian nurses' knowledge and practice of breast self-examination. J Adv Nurs 2009;65:412-6.

7. Odusanya OO. Knowledge,attitudes, and practices of female schoolteachers in Lagos, Nigeria. Breast J 2001;7:1715.

8. Solomon LJ, Mickey RM, Rairiker CJ, et al. There year prospective adherence to three breast cancer screening modalities. Prev Med 1998;27:781-6.

9. Gidey B. Knowledge and Practice of Breast Self-Examination among summer and extension nursing female students in Jima university, Ethiopia. PhD dissertation 2014.

10. Pengpid S, Peltzer K. Knowledge, attitude and practice of breast self-examination among female university students from 24 low, middle income and emerging economy countries. Asian Pac J Cancer Prev 2014;15:8637-40.

11. Akhtari-Zavare M, Latiff LA, Juni MH, et al. Knowledge of Female Undergraduate Students on Breast Cancer and Breast Selfexamination in Klang Valley, Malaysia. Asian Pac J Cancer Prev 2015;16:6231-5.

12. Ameer K, Abdulie SM, Pal SK, et al. Breast cancer awareness and practice of breast self-examination among female medical students in Haramaya University, Harar, Ethiopia. Int J Interdiscipl Multidiscipl Stud 2014;2:109-19.

13. Sarfo LA, Awuah-Peasah D, Acheampong E, Asamoah F. Coping strategies used by people living with HIV at Tetteh Quarshie Memorial Hospital. Med Sci 2013;3:20-3.

14. Azage M, Abeje G, Mekonnen A. Assessment of factors associated with breast self-examination among health extension workers in West Gojjam Zone, Northwest Ethiopia. Int J Breast Cancer 2013;2013:814395.

15. Gebrehiwot H, Hailu T, Giday G. Knowledge on breast cancer and its prevention among women household heads in Northern Ethiopia. PhD dissertation 2013. 